\title{
Los sefardíes de Esmirna durante la Primera guerra mundial: el hambre y la miseria*
}

En el presente artículo, que viene a aportar nuevos datos sobre la historia de los sefardíes del Imperio otomano en el siglo XX, se editan y estudian dos poemas del prolífico autor esmirniota Alexandr (o Alexandro) Ben-Guiat que describen la difícil situación económica de los sefardíes de Esmirna durante la Primera guerra mundial. Los poemas se publicaron en un folleto que apareció en 1918 como suplemento del periódico local $E l$ Meseret, dirigido por nuestro autor. A partir de los datos que los poemas proporcionan, en el artículo se examina su trasfondo histórico, se aportan nuevos datos sobre la vida del autor y se discute su posible presencia en el ejército turco.

Palabras Clave: Primera guerra mundial; sefardíes; Balcanes; edición de textos; Esmirna; poesía sefardí; Alexandro Ben-Guiat; El Meseret; léxico judeoespañol.

Sephardim in Izmir during First World War: Hunger and Misery.- In this article, which provides with more data on the History of Sephardic people in the Ottoman Empire in the $20^{\text {th }}$ Century, two poems written by the prolific author from Izmir Alexandr (or Alexandro) Ben-Guiat are edited and studied. In them, the difficult economic situation of Sephardic people of Izmir during First World War is described. These poems were published in a leaflet appeared in 1918 as a supplement of the local newspaper El Meseret, directed by Ben-Guiat. On the basis of the data provided by the poems, in this article we examine their historic background, we provide with new information relating the author's life, and we discuss on his presumable presence in the Turkish army.

Keywords: First World War; Sephardic people; Balkans; Edition of Texts; Izmir; Sephardic Poetry; Alexandro Ben-Guiat; El Meseret; Judeo-Spanish Lexicon.

Obviamente no vale la pena repetir aquí lo ya dicho hace años ${ }^{1}$, palabras que volví a insertar al inicio de otro artículo posterior sobre el mismo

"El presente artículo se ha elaborado en el marco del Proyecto de Investigación del Plan Nacional: «Sefarad, siglo XXI (2013-2014): Edición y Estudio Filológico de Textos Sefardíes» (ref. MINECO, FF2012-31390).

"elena.romero@cchs.csic.es

${ }^{1}$ Elena Romero, Entre dos (o más) fuegos: Fuentes poéticas para la historia de los sefardíes de los Balcanes (Madrid: CSIC, 2008) págs. 21-22. 
tema: el de la poesía histórica en judeoespañol ${ }^{2}$. Entonces pronosticaba cuántos materiales de tal tipo nos quedan aún por descubrir y expurgar, y cuántos textos nos quedan aún por editar y difundir. Lo que sigue es una muestra más de ello.

Toca esta vez el turno de examinar unos poemas del prolífico autor esmirniota Alexandr (o Alexandro) Ben-Guiat ${ }^{3}$ sobre el tema que adelanto en el título. De la producción literaria de nuestro autor se han ocupado varios investigadores, analizando sus diversas facetas como autor teatral ${ }^{4}$, poeta $^{5}$, traductor y adaptador de novelas ${ }^{6}$ y periodista $^{7}$.

${ }^{2}$ Elena Romero, «Más poemas y coplas sefardíes de contenido histórico», Sefarad 71:1 (2011) págs. 131-200.

${ }^{3}$ Sobre su vida pueden verse los datos que reúne Amelia BARQuín LÓPEz, Edición y estudio de doce novelas aljamiadas sefardies de principios del siglo XX (Leioa: Univ. del País Vasco, Servicio Editorial, Serie Tesis doctorales, 1997) págs. 45-64. Sobre su actividad literaria en general, vid. Elena RoMero, La creación literaria en lengua sefardí (Madrid: Mapfre, 1992) págs. 69, 116, 181, 205-207, 214-215, 227, 237, 244, 247-250, 252-254, 262, 279 y 283.

${ }^{4}$ Vid. al respecto el artículo de Elena Romero, «El teatro entre los sefardíes orientales», Sefarad 29 (1969) págs. 187-212 y 429-440, y 30 (1970) págs. 163-176 y 438-508: 29, págs. 433-434 y notas 150-153; y sus libros El teatro de los sefardíes orientales, 3 vols. (Madrid: CSIC, 1979): vol. I pág. 638, y Repertorio de noticias sobre el mundo teatral de los sefardíes orientales (Madrid: CSIC, 1983) núms. 220, 296-297, 299 y 348. Y en lo que fuera la tesis doctoral de María MarTín Heredia, El teatro sefardí. Edición de textos y estudio de la morfología derivativa nominal (Madrid: Universidad Autónoma de Madrid, oct. 1990), por desgracia inédita, se editan cuatro de sus obras, las tituladas: Mi yernećico, Despośorios de Alḅerto, La boda de Alḅerto y A propóśito de Purim, jurnal de un rećín caśado.

${ }^{5}$ Romero, Entre dos, cap. 7, núms. 49-50 y 52 (vid. también allí en la Introducción general, apdo. 1, nota 5) se he ocupado de su poesía, editando tres poemas de Ben-Guiat dedicados a alabar al sultán Abdul Hamid II y a exaltar la buena convivencia entre turcos y judíos en el Imperio otomano.

${ }^{6}$ Vid. al respecto BARQUín LÓPEZ, Edición, donde se editan las anunciadas 12 novelas publicadas por nuestro autor; a ellas hay que añadir la edición de otra obrita llevada a cabo por Ángel Berenguer AmAdor en su artículo «Los Suvenires del meldar de Alexandr Ben-Guiat», Sefarad 64:2 (2004) págs. 269-288. Vid. también el artículo de Elena RomERo, «Nuevos aspectos de la narrativa judeoespañola», en Proyección histórica de España en sus tres culturas: Castilla y León, América y el Mediterráneo, ed. Eufemio LoREnzo SANz (Valladolid: Junta de Castilla y León, 1993) vol. III, págs. 177-194, y la bibliografía general sobre la novela sefardí allí aducida; especialmente sobre Ben-Guiat en págs. 182, 184-185 y 190.

${ }^{7}$ Se ocupan de su producción literaria en general y de su actividad como periodista en particular Avner LEVI, «Alexander Ben Guiat uterumató la 'itonut vehasifrut hayafá beladino», en The Sepharadi and Oriental Jewish Heritage (Jerusalem: The Magness Press, 1982) págs. 205-212; y BARQuín LóPEZ en Edición (vid. la bibliografía allí citada) 
Y abundando en sus poemas, ese gran bibliógrafo que es Dov Cohen ha tenido la amabilidad, acompañada de la generosidad que siempre le caracteriza, de hacerme llegar un muy interesante hallazgo. Se trata de un folleto que contiene dos poemas de nuestro autor de contenido histórico, cuya edición constituye el objetivo del presente artículo.

Vaya en primer lugar el texto de portada (resalto en negrita las palabras que van en letra cuadrada) ${ }^{8}$ :

Historia / de la guerra. / — / Poeśía / compuesta en Aydín en novembre 1917 / — / Estampada y puḅlicada en Iźmir / en novembre 1918. / _ / Suplemento del Meseret nú' 7 de el 5679 [= 1918]. / Eśmirna.

\section{Características formales del libro y de Los POEMAS}

El librito consta de la portada arriba transcrita, con el dorso en blanco; y contiene los dichos dos poemas: el primero se inicia en pág. [3] (sin numerar) y concluye en pág. 13; y el segundo se inicia en la parte inferior de pág. 13 y concluye en pág. 14. Sigue a esta una página posterior sin numerar en cuya parte central se inserta un grabado con un pájaro reposando en las ramas de un árbol. Los textos de págs. [3] y 14 van en cuerpo mayor que el resto. Cabe señalar la deficiente tipografía del librito, en la que con frecuencia no se distinguen bien las letras, que a veces aparecen mordidas.

El primer poema lleva el epígrafe [pág. 3] de Historia de la guerra, en letra cuadrada de cuerpo mayor y separado del inicio del texto por una pleca, y como colofón (pág. 13) aparece la siguiente precisión:

Compuesto en Aydín mientres la Guerra general en novembre 1917, estampado en Iźmir después de la siñadura del Armisticio en novembre 1918 ,

y en su artículo «Un periódico sefardí: El Meseret de Alexandr Ben-Guiat», Sefarad 57:1 (1997) págs. 3-31.

${ }^{8}$ El libro pertenece a la biblioteca particular de Nissim Caridi (Israel), a quien agradezco de todo corazón el haberme permitido la edición y estudio del texto; uso fotocopia del ejemplar fotocopiado del Instituto Ben Zvi (Jerusalén) L-936.5. 
que va seguida del nombre del autor Alexandr "n Guiat, ajustado a la izquierda y en letra cuadrada. En línea siguiente y centrado aparece un adorno formado por tres estrellitas en pirámide.

El segundo poema lleva el epígrafe (pág. 13), centrado y entre paréntesis: «(Compuesto en Iźmir y ajustado / en november 1918)», y se remata (pág. 14) con las iniciales del nombre del autor-A. B.- en letra cuadrada y ajustadas a la izquierda, seguidas de una pleca ornamental centrada en la página.

En cuanto a los poemas, el primero, que titulo ¿Ubi est Esmirna?: los males de la Gran guerra, consta de 34 estrofas sin numerar, las cuales en repetidas ocasiones -que iré señalando en notas-, están mal partidas -malas particiones que he intentado recomponer- y formadas mayoritariamente por 6 versos generalmente de 12 sílabas y rima $A A B B C C$. Queda manca la estr. 30, formada por 4 versos de rima $A A B B$. Y el segundo, que titulo Alegría por el fin de la Gran guerra y que puede considerarse como un colofón tardío del primero, consta de dos estrofas también sin numerar; la primera de 6 versos y la segunda de 8 con la misma estructura ya descrita.

\section{Contenido DE LOS POEMAS}

En el primer poema, compuesto en noviembre de 1917 y que destila un profundo sarcasmo y una profunda crítica al gobierno del triunvirato turco -al que me refiero luego- que ha llevado al país a la guerra ${ }^{9}$, el autor empieza expresando su deseo de dejar constancia para la posteridad de los terribles males que la guerra ha producido y del sufrimiento que está causando (estrs. 1-3). Describe brevemente las penurias de los

${ }^{9}$ Sobre tal actitud, que contrasta con la que he expresado en nota 5 supra, y otros varios asuntos al respecto vid. Eliezer PAPo, And Thou Shalt Jest with Thy Son: JudeoSpanish Parodies on the Passover Haggadah (Jerusalem: Ben-Zvi Institute et al., 2012 [en hebreo]) vol. I, págs. 147-196. Sobre los sentimientos de amor y desamor de los sefardíes hacia el Imperio otomano, tema manido y deformado según la opinión personal de cada analista, pueden verse, por ejemplo, las reflexiones de ROMERo en Entre dos, cap. 16, págs. 761-776, capítulo titulado «A toro pasado...: Alabanza y detrimento del Imperio otomano», así como los textos allí editados en los que se da una de cal y otra de arena. 
soldados movilizados y de las mentiras que se les cuentan (estrs. 4-5) $\mathrm{y}$ vuelve a incidir en los males de la guerra, expresando el ubi est de la antes feliz y rica Esmirna (estr. 6), motivo que subyace a lo largo de todo el texto y que volvemos a encontrar más tarde (estr. 16) explícitamente expresado. Tras ello y sin más transición el autor comienza (estr. 7) a lamentar la desmesurada alza de precios que han sufrido numerosos productos, tema que ocupa la gran parte del poema ${ }^{11}$. Con humor más que negro invoca a vendedores ya muertos y a otros desaparecidos por la crisis; y así conjura a los ya fallecidos David Baruj (estrs. 8-10) -vendedor de productos dulces- y al cervecero Cheliḅón Kohén (estr. 12), que según se desprende de lo dicho, debieron ser personajes conocidos en la ciudad. Alude después a los desaparecidos vendedores de halvá (estr. 11) y de otros varios productos (estr. 13); así como a los vendedores ambulantes de raquí y a la desesperación actual de los taberneros (estrs. 14-15).

Pasa después a referirse a los precios disparatados de otros productos de primera necesidad: petróleo y velas (estr. 17), las cuales ya no se usan ni para honrar a los muertos; prendas de vestir y tejidos (estrs. 18-22); jabón y leña (estr. 23), anunciando una tremenda piojera ante la falta de higiene; y cerillas de fabricación austriaca (estr. 24), pueblo que ahora se ha convertido en denostado enemigo. Insiste al autor en la escasez de alimentos esenciales, como azúcar, café, etc. (estr. 25) y menciona una serie de ricos guisos de antaño hoy desaparecidos y que se han tenido que sustituir por otros más humildes y baratos (estrs. 26-31). Como conclusión vuelve a expresar su dolor por la guerra y por la terrible situación que todos padecen (estrs. 32-33), y, deseando

${ }^{10}$ Sobre tales infundios, que se hacían circular para animar a la tropa y a los civiles que esperaban ansiosos en ciudades y pueblos, cabe repetir aquí las palabras que recoge Henri Nahum, Juifs de Smyrne XIX ${ }^{e}-X X^{e}$ siècle (Paris: Aubier, 1997) cap. IX, nota 9 (pág. 256): «La grand-mère de l'auteur du présent ouvrage lui recontait: "On nous annonçait chaque semaine une grande victoire. Nous pavoisions. Un beau jour, on nous a dit que la guerre était perdue"».

${ }^{11}$ Vid. en Romero, Entre dos, cap. 12, núms. 111 y 115, las coplas tituladas El precio de las vituallas y La crisis del '14 que desarrollan temas parecidos. Sobre la falta de abastecimiento y el hambre en Esmirna vid. también NAHUm, Smyrne, cap. IX y la bibliografía allí anotada. 
los peores males a Enver ${ }^{12}$, solo espera que la bondad divina les lleve a vivir tiempos mejores (estr. 34).

Destila ya otro talante el segundo poema, escrito, según nos dice su autor, en noviembre de 1918 y tras la firma del armisticio. Después de dar fervientes gracias a Dios por haber hecho caer a los enemigos (estr. 1), resume (estr. 2) el fin de la guerra: la intervención de los americanos y de la Entente, la huida de Enver y Tal'at, y la cesión de los ingleses a los judíos de un satíricamente llamado «reinado» ${ }^{13}$.

\section{EDICIÓN DE LOS TEXTOS}

Veamos en primer lugar los textos. Son míos los títulos, así como la numeración y partición de algunas estrofas, e igualmente es mía la puntuación y versalización; indico las páginas del original en negrita precedidas de barra inclinada, todo ello volado. En Glosario al final del artículo se recogen las palabras de difícil comprensión.

\section{1. ¿Ubi est Esmirna?: Los males de la Gran guerra:}

\section{${ }^{/[3]}$ Historia de la guerra ${ }^{14}$}

1 Una poeśía quis̀e yo asentar, todo lo que estamos pasando contar, siendo es maravía cómo rellevamos estos males que nośotros somportamos. Y es también aínda de maraviar cómo esto lo estamos pudiendo chequear.

\footnotetext{
${ }^{12}$ De quien volveré a ocuparme después. Vid. en Romero, Entre dos, cap. 12, núms. 118 y 120 las coplas tituladas La caída de Enver Pachá y Enver parte de Turquía.

${ }^{13} \mathrm{La}$ inmensa y esperable alegría con la que los sefardíes acogieron el final de la contienda queda reflejada en numerosos textos en prosa y en verso. Un ejemplo de ello es lo que al respecto dice Eliyá R. Carmona en su Hagadá de la guerra general, que se publicó en Constantinopla hacia 1919 y de la cual se edita un pequeño fragmento en RoMero, Entre dos, cap. 12, pág. 603.

${ }^{14}$ Como ya he dicho arriba, al epígrafe le sigue una pleca.
} 
2 Poeśías como la que quero escribir quedan muchas većes como un suvenir y poeśías como la ${ }^{15}$ de estos años quedan en većes para años y paños ${ }^{16}$, quedan de suvenir para nuestros hijos que las meldan también a nuestros fitijos.

3 ¿Cuálo no diré que no dará a pensar?, ¿cuálo no escribiré que no me hará cansar?

No son vidas estas que estamos llevando, son munchos dertes los que estamos trabando; ${ }^{14}$ dertes sin escapar, males sin amenguar, sin tener ninguno por hablar o llorar.

4 Día y noche en la piedra laborando, más mucho de Pitom y Ra'amsés fraguando ${ }^{17}$. $\mathrm{El}^{18}$ sacaquié ${ }^{19}$ tenemos cien y un raśgón, con dos mil y un remendos el patalón ${ }^{20}$; de piojos también el enverié ${ }^{21}$ lleno deśde cuatro años con este enverno.

5 Sin tener ni un minuto por descansar, aunque ven que no hay del todo avanzar. El tufenc al hombro todo el día estamos, la noche también como el día velamos

\footnotetext{
${ }^{15}$ Habríamos esperado las.

${ }^{16}$ Formulación humorística, ya que la expresión habitual, según la recoge Joseph Nehama en su Dictionnaire du judéo-espagnol (Madrid: CSIC, 1977), s.v. áño, es, como en español, «años y años».

${ }^{17}$ Se refiere a las ciudades que, según Éx 1:11, construían los judíos esclavizados por el faraón de Egipto.

${ }^{18}$ Habríamos esperado al.

${ }^{19}$ Aunque la letra inicial está emborronada, la palabra parece estar escrita סאקאקיי $<s^{\prime} k$ 'kyy $>$, que también podría transcribirse sacaquii. Por lo que se dice luego y por el contexto, debe tratarse de una prenda del uniforme militar, que hay que poner en relación con ngr. бакка́кı 'chaqueta', aquí probablemente 'guerrera'.

${ }^{20}$ Así escrito, y no pantalón, lo recoge también Nehama, Dictionnaire, s.p.v.

${ }^{21}$ Gorro o casco cónico de los soldados turcos, forrado de tela, también llamado kabalak o başlık; su nombre deriva del ministro de la guerra Enver Pachá, que fue quien introdujo su uso. Vid. http://www.ottoman-uniforms.com/ww1-1915-to-1918-period-turkishuniforms/, enlace que debo a la amabilidad de Aitor García Moreno.
} 
$\mathrm{y}$, si alguna vez dićen que ya ganimos, es que un otro castío ya pedrimos.

6 Curiośo habe seido lo de esta guerra que alborotó adeta toda la tierra; a todos nos trujo hasta los petahim, a dos pasos de la puerta del bet hahayim. Lo bueno de antes se fue sin más venir, la vida más no vale con este ỵivir.

$7{ }^{15} \mathrm{De}$ cien tantos pujaron todas las cośas, no estamos más caminando sobre rośas. Los muertos de antes se estremecerían si los precios de agora ellos oyirían, las orejas de vista se taparían, al foyo atrás de vista se irían.

8 David Baruj ${ }^{22}$, ¿ónde estás? Levanta, mira y de alma y de corazón suspira de ver el precio de la almendra y la miel que se hiźo mucho más amarga de la fiel: la almendra pujó hasta cerca trećientos y miel de panal hasta más de doćientos.

9 Halvá de almendra ¿cómo ibas a vender?, mira que es cośa que no se puede entender; y de la alhajúu ${ }^{23}$ te repentirías si el precio de la nueź también oías, porque tú eras día entero coriendo, a metalic a metalic recoǵendo.

10 Salep no venderías por seguro más, porque no ibas a yetišear parás; Esmirna.

${ }^{22}$ Según se dice luego (estrs. 9-10), parece tratarse de un pastelero muy conocido en

${ }^{23}$ Nehama, Dictionnaire, s.v. aljašú explica: «sorte de nougat fait de biscuit en poudre ou de chapelure de pain azyme, d'amandes, de noix et autres fruits grillés, d'epices, le tout bien pilé et cuit dans du miel»; y el $D R A E$, s.v. alajú de forma similar: «pasta de almendras, nueces, y, a veces, piñones, pan rallado y tostado, especia fina y miel bien cocida». 
${ }^{16}$ y arope más Pésah ${ }^{24}$ no venderías

y de subia también te pasarías.

Ir mercando todo a precio de oro, vendiendo con deretimiento de coro.

11 Halvaĝís de Ergat Baźar ${ }^{25}$ ¿qué vos hićiteš?, ¿en qué cantón fuíteš y vos esconditeš?:

a dos liras se vende y con patenta aquea halvá de grušes tres y trenta.

Aquea de las noches de alhad se perdió, cayó en Iźmir una maldición del Dio.

12 Y tú también Cheliḅón Kohén, el biero, muncho conocido en Iźmir entero, ¡cuál bien no veas y cuál negro no verás! Si por un quief del foyo te levantarás, abre los culaques y roe con dicat, mientres que estás asentado ahí rahat.

13 Borecas no hay más de aqueas sabrośas, según no venden más munchas otras cośas. El bollo de un metalic pujó a diez, güevo ḥaminado ¿por ónde más lo ves?, ${ }^{17}$ porque hasta vente metaliques vendieron, afilú que pollos de adientro salieron ${ }^{26}$.

14 ¿Ónde estáš también vośotros coltucchís que adeta, como si fueraš noḅetchís, hasta la puerta de la taberna veníaš, a dos un metalic raquí nos servíaš ${ }^{27}$ ? ¿Ónde vos fuíteš vos, hombres de piadad, que adeta con nos todo era hermandad ${ }^{28}$ ?

\footnotetext{
${ }^{24}$ Es decir, nunca más venderías arrope en Pésạ.

${ }^{25}$ Nombre de un popular mercado de Esmirna.

${ }^{26}$ Frase humorística en la que se viene a decir que, debido al exagerado precio de los huevos, para cuando se venden ya han incubado pollitos.

${ }^{27}$ Es decir, nos servíais dos raquíes por un metalic.

${ }^{28}$ La alusión a la hermandad puede indicar que los vendedores ambulantes aludidos no eran judíos.
} 
15 A una lira pujó aquel duźico ${ }^{29}$; el que bebe es que tiene fernetico ${ }^{30}$. El tabernero no sabe más lo qué haćer, adeta parece que se va deśhaćer. A vente metes ${ }^{31}$ pujó el raquí sin meźé, con beberlo también en seco biź biźé.

16 Se fue del mundo aquel sorte de trato, no quedó agora más nada barato.

Se fue sin más venir aquel todo bueno del cual Iźmir era tašteado ${ }^{32}$ lleno; se fue todo aquel famośo berequiet de cuando dećíamos: «iYiné benivet!» ${ }^{33}$.

$17{ }^{18} \mathrm{~A}$ trećientos se vende agora el petrollo, no lo toca ni el que tiene meollo. La candela costa mil y haločentos, no sé si encienden ni para los muertos; la noche comemos en la escuridad, el día solo es que vemos claridad.

18 Vente liras un paltó, trenta un vestido, precio $^{34}$ que nunca los tuvimos sentido.

${ }^{29}$ Nehama, Dictionnaire, s.v. dúziko explica: «eau-de-vie grecque».

${ }^{30}$ Lo que Nehama, Dictionnaire, s.v. fernét traduce como 'ivre, pris de boisson', explicando que: «Fernet est une variété de liqueur». Debemos, pues, entender la expresión «tener fernetico» como 'ser un borracho empedernido'.

${ }^{31}$ Escrito מיטיס, aunque la lectura de la tet resulta dudosa; obviamente se trata de una moneda y quizá se trate de un error o de una abreviación de tc. metelik, metalik, que en jsp. y pl. suele ser metaliques.

${ }^{32}$ Escrito טאשטיאדו, que entiendo que hay que poner en relación con tc. taş'desbordar, rebosar'; es decir, que, antes de la guerra, Esmirna rebosaba hasta el colmo de toda suerte de cosas buenas.

${ }^{33}$ Las comillas y admiraciones (una al final) en el texto. La expresión está escrita ביניבייט ייני, cuyo significado y etimología no tengo muy claros y por tanto resulta dudosa mi transcripción. Un poco a la desesperada se me ocurre proponer tc. yine 'de nuevo' + benevbet 'alternativamente', cuyo confuso sentido sería 'de nuevo por turno, alternativamente'; tampoco ayuda mucho entender la primera palabra como tc. ye'comer', ni como hb. 'ני" yení 'mi vino' y también 'parecido al vino, vinoso'.

${ }^{34}$ Habríamos esperado precios o más adelante $l o$. 
Una fez, seš meĝitim ${ }^{35}$; una mejor, diez; el que no tiene viste la vieja arovés. Chapines adeta el par ocho liras y pantuflas manco de tres no me digas.

19 Los chorapes todos llenos de buracos, no son ni para caminar con tacos; y los tacos también están tanto caros, que adeta para mercar están $\operatorname{raros}^{36}$. Chanaca se hiźo ya dijimos la fez, de los bodres sale una libra de pez ${ }^{37}$.

20 Por pišcul hay dos tres hebras encolgando y la corona se quitó no sé cuándo. ${ }^{19} \mathrm{Riś}$ as por riźás ${ }^{38}$ tienen solo los ricos y nośotros nos pasamos con trapicos. Ansí se completa nuestra vestimienta, todo justo de la sal a la pimienta.

21 Un top de cáḅot vale cuarenta liras y a la hasés ¿por ónde tú la miras? Un pico de chit vale hasta un megit y dos y por catifé, en fin, no demandéš vos.

Si sabíaš que lo que mos daban por campión no yatišea a mercarlo hoy un señorón.

22 El algodón pujó un ojo de cara y la lana también está tanto cara que ni colcha ni colchón está quedando,

${ }^{35}$ Escrito מיגייטים, que podemos suponer un compuesto de tc. mecit + la desinencia hb. de pl. msc. -im.

${ }^{36}$ Aquí se corta la estrofa mediante el espacio habitual.

${ }^{37}$ Es decir, de grasa; vid. DRAE, s.v. pez $z^{2}$. Este verso queda tipográficamente unido a la estrofa siguiente.

${ }^{38}$ Juego de palabras entre jsp. riśas ('risas') y tc. riźás 'pañuelos', que en aljamía se escriben igual. Entiendo que quiere decir que son los ricos los únicos que están felices por poder comprarse pañuelos, idea en la que se insiste en estr. 33, v. 5.

${ }^{39}$ Que Nehama, Dictionnaire, explica: «calicot, toile de coton dont on fait de draps de lit, des culottes, etc.». 
en tablas cuas̀ ${ }^{40}$ nos estamos echando; y por sábanas no quere demandado ${ }^{41}$ si las habemos diez većes remendado.

23 A cien y cincuenta se vende el jabón y a cien uno preto como el carbón; y la leña, siendo cara este año, no hay ningún molde de haćermos baño. ${ }^{10} \mathrm{Bien}$ presto tendremos y piojo con cola bastante grande por mandarlo a la escola.

24 De cinco que mercábamos un metalic, de sesenta que nos daban por un bešlic, aribimos a tomar a un altelic y también vendida con mucho quieḅarlic una cajica de espirtos austriaco ${ }^{42}$, del que al nemsí encisco y embataco ${ }^{43}$.

25 Zúcar nos vendieron hasta cuatrocientos, café del bueno hasta novecientos, pimienta adeta a mil y quinentos y aroz del muy negro hasta trećientos; macarón y miśmo fideo a sesenta, patata por patata a grušicos trenta.

26 Agora hablaremos de las comidas, a una a una todas descogidas.

Muchas noches en sirá todo garbanzos y bulgurico cuando estamos cansos ${ }^{44}$. Habas y ervía, en griña en griña, todo bullido en olla y con leña.

\footnotetext{
${ }^{40}$ Escrito קואזי

${ }^{41}$ Es decir, no hay ni que preguntar.

${ }^{42}$ Habríamos esperado austriacos, de referirse la palabra a espirtos, o austriaca, de referirse a cajica.

${ }^{43}$ En vs. 1-3 el autor detalla cómo ha ido subiendo de forma disparatada el precio de las cajas de cerillas de fabricación austriaca (v. 5), plasmando en el último verso, cuya formulación no queda clara, su animadversión a los austriacos en cuya guerra se han visto involucrados.

${ }^{44}$ Sigue a este verso el espacio habitual de separación de estrofa.
} 
$27{ }^{/ 11}$ Caro el quiemur y el calayileado ${ }^{45}$, por esto guiśamos en envedreado ${ }^{46}$. Pešcado, hígado, quieftés de meollo y de vez en vez algún caldo de pollo: esto no quedó más, esto despareció, dirían miśmo que esto nunca no mos nació.

28 Con prasa afilú ya mos contentamos, si barata a lo menos la topamos; y a la espinaca bendećiríamos si día cada día la topábamos ${ }^{47}$. Sardelas, pešcado a grušes ochenta y carne fidionda a grušes setenta ${ }^{48}$.

29 Meollo, un cabral, hígado a noventa, pachás sućias las cuatro grušes cincuenta; pan tierregośo a un cuarto de lira y hasta un meĝid un vaśo de bira ${ }^{49}$. Por calabaza y prasa no demandéš, en ‘áyim ${ }^{50}$ y los oídos no vos tapéśs ${ }^{51}$.

30 Solo sabeldo cómo por maravía que bamiya se vendió a una amaría. ${ }^{/ 12}$ Ervía y fasulia cart a un meĝit, fijón apenas lo vemos por un šešit ${ }^{52}$.

${ }^{45}$ Escrito קאלאייליאדו; como se está hablando de materias para encender fuego, entiendo que hay que poner la palabra en relación con tc. galiya, galiye 'negro', refiriéndose al carbón de encina, o con tc. kala- 'apilar madera para quemar', y no con tc. kalaylı 'estañado'.

${ }^{46}$ Sigue a este verso el espacio habitual de separación de estrofa. Entiendo que quiere decir que, ante el precio del carbón y de la leña, deben encender el fuego con madera aún verde, que no está del todo seca.

${ }^{47}$ Sigue a este verso el espacio habitual de separación de estrofa.

${ }^{48} \mathrm{El}$ verso aparece unido a lo que sigue.

${ }^{49}$ Sigue a este verso el espacio habitual de separación de estrofa.

${ }^{50}$ Escrito por error אנעים; cfr. hb. עניים / 'enáyim 'ojos'.

${ }^{51} \mathrm{El}$ verso pegado a lo que sigue.

${ }^{52}$ Aquí espacio de separación de estrofa, que queda manca. 
31 Espinaca de la fresca seš [] $]^{53}$ ochos, a tres y cuatro la de quitar los ojos; y hasta una col del quiraguí quemado por tres cuarticos de megit fue mercado. Y el Beledié ciego mira de enfrente ${ }^{54}$, aunque estos precios es en megit vente.

32 Concluśión es que negra estuvo la hora de cuando empezó esta guerra de agora y parece, en fin, que ya era carar que saliéramos de este énremo muladar. Ya no quedó más con cuálo valiarmos, no tenemos más nada de ónde enramarmos.

33 Ya caminamos enteros remendados, ya quedimos descalzos y deśḅragados, ya no hay más en caǰa de cuálo trocar ${ }^{55}$, ya estamos enteros un asco de tocar. Ni riźás nos quedó más para amocarmos, ni uñas en manos para arascarmos.

$34{ }^{/ 13} \mathrm{Si}$ el Dio no mira y no se apiada, a este Enver no le da la landrada, es que escura aínda la tendremos, más días escuros aínda veremos. Ma el Dio, que hiźo siempre maravías, nos hará ver con bueno mejores días.

\section{Alegría por el fin de la Gran guerra}

1 Después de escribir esta poeśía, el Dio del cielo hiźo su maravía; maravía que solo del cielo ariba, maravía que haće el Dio de ariba. ${ }^{/ 14} Y$ es que en octubre de este año nuestros enemigos cayeron al caño.

\footnotetext{
${ }^{53}$ Siguen un par de letras mordidas que no puedo identificar.

${ }^{54}$ Es decir, se desentiende, hace la vista gorda.

${ }^{55}$ Es decir, ya no queda en el baúl (caja) ninguna prenda con la que mudarse.
} 
2 Cayeron al caño nuestros enemigos y para ellos no hubo más aḅrigos. La América y la Antant nos salvaron, Enver y Talaat la fuyida tomaron. Más nunca días pretos no vamos a ver, la landre le dio a este énremo Enver. Nuestro enemigo en fin fue atemado y a los judiós el ingléś nos dio reinado.

\section{TRASFONDO HISTÓRICO}

Para comodidad del lector y para la correcta comprensión de los poemas editados resulta imprescindible hacer siquiera un breve y muy somero recordatorio histórico de los acontecimientos a los que en ellos se alude, acontecimientos que por otra parte son conocidos de todos ${ }^{56}$.

La Primera guerra mundial, también llamada Gran guerra, se desarrolló entre el 28 de julio de 1914 y el 11 de noviembre de 1918, suscitada -amén de por el asesinato del archiduque Francisco Fernando, heredero de Austria, perpetrado el 28 de junio de 1914 en Sarajevo (Bosnia)- por los deseos de Alemania de conseguir la hegemonía europea.

El 28 de julio de 1914 Austria-Hungría declaró la guerra a Serbia -cuya resistencia no consiguió doblegar hasta 1915-, mientras que Alemania hacía lo mismo con Rusia el 1 de agosto y con Francia el 3 del mismo mes.

En pocos meses las fuerzas de Europa quedaron distribuidas en dos campos: por un lado, los imperios centrales de la llamada Triple Alianza, formada por Austria-Hungría-Alemania y de la que Italia se había desmarcado; y por otro la Triple Entente, integrada por Rusia, protectora de Serbia, Francia, aliada de Rusia, y Gran Bretaña, aliada de Francia y signataria de la neutralidad de Bélgica, y con ellos, claro está, los dos países agredidos: Serbia, en primer lugar, y Bélgica, poco después.

La Triple Alianza recibió las aportaciones de Bulgaria y de Turquía; pero voy a centrarme aquí solamente en el papel de Turquía, que dirigida por la mano del germanófilo triunvirato en el poder, Enver Pachá, Tal'at

\footnotetext{
${ }^{56}$ Puede verse un resumen más amplio en Romero, Entre dos, cap. 12.
} 
Pachá y Cemal Pachá, entró oficialmente en la guerra el 29 de octubre de 1914, aliada, para su mal, en el bando que habría de ser el de los perdedores.

Por otro lado, en el transcurso de la guerra el núcleo original de la Triple Entente -franceses, ingleses y rusos-, denominados ahora Aliados, se vio incrementado con otros contingentes, de los que aquí solo me interesa mencionar a Estados Unidos (desde el 2 de abril de 1917).

Ante el empuje de los Aliados, entre el 21 de marzo y el 11 de noviembre de 1918 se desarrolló la última fase de la guerra, capitulando los países balcánicos en liza. Turquía lo hizo en Mudros el 30 de octubre de 1918, provocando la huida del triunvirato en el poder: Enver -que se produjo el 2 de noviembre de 1918-, y Cemal y Tal'at, con los que los Aliados, que ocuparon Constantinopla el 13 de noviembre de 1918, se negaron a tratar. Enver acabó sus días luchando contra los bolcheviques en el Turquestán, y Tal'at fue asesinado en Berlín en $1921^{57}$. En los momentos de la capitulación, la situación de los territorios asiáticos del ya muerto Imperio otomano era la siguiente: Mesopotamia y Samsun (mar Negro) en manos de los ingleses; los franceses ocupando Siria y Cilicia (Adana); y los italianos estacionados en Konya y Antalia (Adalia).

De esta manera, pocos días antes de que Austria-Hungría -el 3 de noviembre- y Alemania -el 11 del mismo mes- reconociesen su derrota, la guerra había concluido en los Balcanes.

El 18 de enero de 1919 se inauguró en París la conferencia interaliada, preparatoria de la paz de Versalles, dirigida por el denominado «grupo de los cuatro»: Estados Unidos, Gran Bretaña, Francia e Italia. La conferencia reunía a veintidós estados, figurando entre los vencidos Alemania, AustriaHungría, Turquía y Bulgaria. Para llevar a cabo tan complicada tarea, se nombraron cincuenta comisiones que redactaron tratados de paz parciales.

El 28 de junio de 1919 se firmó el tratado de Versalles, impuesto a Alemania, y el 4 de agosto de 1920 el de Sèvres con Turquía, último de los acuerdos de paz, rematado casi dos años después de acabadas las

${ }^{57}$ Sobre la suerte final de los mencionados vid., respectivamente, Nisim M. BENEZRA, Une enfance juive à Istanbul (1911-1929) (Istanbul: Les Éditions Isis, «Cahiers du Bosphore XIV», 1996) pág. 79; y Feroz Ahmad, «The Special Relationship: The Committee of Union and Progress and the Ottoman Jewish Political Elite, 1908-1918», en Jews, Turks and Ottomans: A Shared History, Fifteenth Through the Twentieth Century, ed. Avigdor Levy (Syracuse: University Press, 2002) págs. 212-230: 217. 
hostilidades. Tanto este último tratado como el de Versalles arriba mencionado significaban los desmembramientos respectivos de los Imperios otomano y austro-húngaro.

Turquía, entre los otros muchos territorios que perdía, cedía también sus territorios en Asia continental: como mandato de la Sociedad de Naciones, Siria era encomendada a Francia, y Mesopotamia y Palestina a Inglaterra.

Hay que recordar también aquí la llamada Declaración Balfour. El 2 de noviembre de 1917, Lord Arthur Balfour, ministro de Asuntos Exteriores de Gran Bretaña, con el fin de atraerse la simpatías de los sionistas de Europa, se comprometió, en carta dirigida a Lord Walter Rothschild, a apoyar la constitución de un Estado judío en la por entonces posesión turca de Palestina, cuya administración al acabar la guerra y según acabo de mencionar, le fue encomendada a Gran Bretaña por la Sociedad de Naciones.

\section{COMEnTario}

Veamos ahora cómo encajan los datos que nos proporcionan los textos en el rompecabezas histórico que he expuesto y para ello seguiré el hilo conductor de los poemas.

En estrs. 4-5 Ben-Guiat se refiere a las penurias de los soldados y la primera pregunta que surge es la de si se está refiriendo a experiencias personales o si está generalizando. Y para ello resulta clave determinar la edad que tuviera nuestro autor para las calendas de noviembre de 1917, fecha de composición del primer poema, pero que habría que retrotraer quizá al invierno de 1914 a tenor de lo que el autor nos dice en ¿Ubi est? v. 4f: «deśde cuatro años con este enverno».

Yo misma ${ }^{58}$ cifraba su fecha de nacimiento en ca. 1869, siguiendo los datos de Gaon (1937) ${ }^{59}$ quien dice (traduzco del hebreo) que «falleció en el invierno de 1924 a la edad de 55 años», fecha que el propio Gaon rectifica posteriormente $(1965)^{60}$, al decir que murió a la edad de 65 años,

\footnotetext{
${ }^{58}$ Teatro, vol. I, pág. 638 y Creación, pág. 279.

${ }^{59}$ Moshe David Gaon, Yehudé hamiźrah beEreŝ Yisrael [...]: ḥélec šení (Jerusalem: Azriel, 1938) pág. 199.

${ }^{60}$ Moshe David Gaon, A Bibliography of the Judeo-Spanish (Ladino) Press (Tel Aviv: Ben Zvi Institute-Jewish National and University Library, 1965 [en hebreo]) pág. 83.
} 
lo que retrasaría su nacimiento a 1859, poniendo en duda Barquín López ${ }^{61}$ ambas fechas con argumentos muy razonables.

Es de nuevo Dov Cohen, con su profundo conocimiento de cuanto a Esmirna se refiere (y mucho más), quien viene a precisarme una serie de datos. Esto es lo que me dice mi querido amigo en un e-mail reciente (mayo 2013), contestando a mis preguntas (re-escribo en español sus respuestas):

Para el año de nacimiento de Ben-Guiat tengo dos fuentes de su época:

1. En un censo hecho por la comunidad de Esmirna en 1899, Alexandro Ben-Guiat figura como gaćetero, nacido en el año musulmán de 1283, que corresponde a las fechas gregorianas de entre 16/05/1866 a 4/05/1867.

2. En su obituario, publicado en El Tiempo de Estambul (16/10/1923), figura que murió a los 60 años de edad. Así que habría nacido en el año 1863.

Las necrologías no siempre eran muy precisas. De modo que el año 1866 me parece el más próximo a la realidad.

Ben-Guiat murió el día 23 de tišrí de 5684 (= 3/10/1923), según el registro de la comunidad. Si realmente nació entre 1866-1867 tenía entonces entre 56 y 57 años. Gaon dice que tenía 55 y El Tiempo 60.

Admito que, según los cálculos de Cohen, nuestro autor tuviera en 1917 la edad de 51 años y por tanto 48 en 1914. Al respecto de la edad de movilización durante la Primera guerra mundial, Erol Haker ${ }^{62}$ precisa que en 1914 se llevó a cabo una movilización general, manteniéndose todavía el impuesto denominado bedel para la exención del servicio militar, el cual desapareció en 1915, ya que Enver Pachá, por imposición de los alemanes $^{63}$, canceló el bedel, siendo reclutados sin excepción todos los

${ }^{61}$ Edición, págs. 45-46, nota 8.

${ }^{62}$ Erol HaKer, Once upon a Time Jews lived in Kirklareli: The Story of the Adato Family, 1800-1934 (Istanbul: The Isis Press, 2003) págs. 124 y 126.

${ }^{63}$ Vid. Haker, Adato Family, pág. 126; Benezra, Une enfance juive, quien adelanta la fecha de tal medida a 1914; en tanto que Avner Perez (ed.), Hayim Nahmias, Diario 1917-1918: Memorias de un soldado en la armada otomana durante la Primera guerra mundial (Instituto Maale Adumim 2004 [en hebreo y judeoespañol]) pág. 20, la retrasa hasta el último año de la guerra. 
hombres entre los veinte y los cuarenta y cinco años, ampliándose la edad de reclutamiento en el segundo año de la guerra hasta los cincuenta ${ }^{64}$.

Aunque algunas fechas no terminen de cuadrar, quizá venga a justificar la presencia de Ben-Guiat en el ejército turco en 1914 el siguiente comentario que apareció en el periódico de Nueva York La América 1/21 (17 ab 5671 / 11 agosto 1911) pág. 2c, donde se dice que lo de la edad de llamada a filas a los 45 años ya existía desde 1911:

La ley de armada en Turquía.- Según anunciamos en nuestro último número, cada súdito otomano de edad de 21 fin 45 años, sin diferencia de nacionalidad, debrá ser soldado $[\ldots]^{65}$,

$y$, por otra parte otros autores precisan que los judíos fueron reclutados por primera vez con motivo de las sublevaciones de Albania de 1910 y 1912, y de la Guerra turco-italiana por Tripolitania de 1911-1912 .

De lo arriba dicho se desprende que nuestro autor podría estar hablando de experiencias personales sufridas en algún momento de estos períodos bélicos; sin embargo, no puedo por menos de expresar ciertos recelos, que son los siguientes. Como era muy frecuente en el caso de los periódicos sefardíes, sus editores los redactaban ellos mismos de cabo a rabo. Tal es el caso también de Alexandro Ben-Guiat ${ }^{67}$, o lo que es lo mismo, sin su presencia física en Esmirna su principal periódico $-E l$ Meseret- tendría que haber dejado de publicarse. Y es el propio Levi quien siembra mis dudas diciendo: primero (op. cit. pág. 207), que en 1914 el periódico pasó de ser semanal a aparecer dos veces en semana y poco después a ser diario, pero que (traduzco del hebreo) «con el estallido de la guerra volvió de nuevo a ser semanal»; y más adelante (op. cit. pág. 208) que el periódico, que habitualmente constaba de 8 hojas, «con el estallido de la Primera guerra mundial bajó la extensión de $E l$ Meseret a 4 hojas».

${ }^{64}$ A tales levas alude la copla que titulo La caída de Enver Pachá publicada en Romero, Entre dos, cap. 12, núm. 118, estr. 8.

${ }^{65}$ Se reproduce el texto completo en Romero, Entre dos, cap. 10, pág. 486.

${ }^{66}$ Vid. al respecto Romero, Entre dos, pág. 485 y la bibliografía allí anotada.

${ }^{67}$ Vid. al respecto lo que dice Levi, «Alexander Ben-Guiat», pág. 207. 
Resumiendo, si tras el inicio de la guerra el periódico seguía apareciendo, me inclino a pensar que, al menos durante un tiempo, Ben-Guiat seguía en Esmirna, lo que no puedo precisar es por cuánto tiempo; pero lo que sí sabemos, según nos dice él mismo, es que en 1917, cuando escribe su primer poema, nuestro autor se encontraba $-i$ acantonado?- en la ciudad de Aydín, al sureste de Esmirna.

También nos dice Ben-Guiat en ¿Ubi est? (vs. 4a-b) que se pasaba el día cortando piedras. En otro lugar me he ocupado ampliamente de la participación de los judíos en el ejército turco ${ }^{68}$ y de cómo el servicio militar se hacía especialmente duro para ellos por varias cuestiones, entre las que cabe señalar aquí la de que a los soldados no musulmanes se les utilizaba mayoritariamente para los trabajos más duros de apoyo al ejército, tales como abrir, zanjas, despejar caminos, etc. Que los judíos actuaban como obreros del ejército turco, concretamente partiendo piedras, es algo que ya encontramos en el poema que titulo Diario de un combatiente en la Primera guerra mundial ${ }^{69}$, donde entre otras muchas cosas se dice (v. 2a): «Piedras era yo partién por tierras y caminos», y se describe así mismo el mal equipamiento de los soldados (estrs. 3-4), como hace nuestro autor en ¿Ubi est? estr. 4. Tal Diario apareció, junto con otros tres poemas que se ocupan de la Gran guerra ${ }^{70}$, en un suplemento de El Meseret de Esmirna (s.d., ca. 1918 o 1919) y sin nombre de autor, por lo que no puedo afirmar que los hubiera compuesto Ben-Guiat.

En cuanto a que se pasaban el día con el fusil al hombre (¿Ubi est? estr. 5), es el propio Ben-Guiat en su librito La Haġadá de [Be]n-Guiat ([Esmirna 1919]), quien en relación también con la Primera guerra mundial escribe (págs. 1-2) las siguiente palabras que resultan próximas a las de nuestro poema:

¿Cuánto fue demudada la guerra la esta más que todas las guerras?: [...] que en todas las guerras todos éramos asentados mirando de enfrente, y en la guerra la esta todos nos el tufenc al hombro $[\ldots]^{71}$.

\footnotetext{
${ }^{68}$ Vid. Romero, Entre dos, cap. 10, apdo. C.

${ }^{69}$ Editado en Romero, Entre dos, cap. 12, núm. 121.

${ }^{70}$ Editados en Romero, Entre dos, cap. 12, núms. 118-120.

${ }^{71}$ Vid. Romero, Entre dos, cap. 10, pág. 487. Tal texto lo edita completo PAPO, And Thou, vol. II, págs. 45-63 (vid. mi cita en págs. 46-47).
} 
Ya han quedado identificados arriba los personajes de Enver y Tal'at, mencionados por Ben-Guiat en ambos poemas (¿Ubi est? estr. 34 y Alegría estr. 2).

En cuanto a la alusión de Ben-Guiat en Alegría (v. 2h) a que los ingleses dieron un «reinado» a los judíos, está refiriéndose a la también arriba mencionada Declaración Balfour de 1917, tema que encontramos también en la copla que titulo Enver parte de Turquía (estr. 10), escrita hacia 1919, donde se dice que los judíos celebrarán el próximo Purim en Palestina, y en el poema Desconfianza en el futuro de 1919 (estr. 7) De como unos años después quedaron frustradas tales esperanzas queda plasmado en la copla que titulo La pérfida Albión de $1939^{73}$.

Para terminar cabe decir que -carpe diem- poco habían de durarle las alegrías a Ben-Guiat, quien en noviembre de 1918 celebraba el fin de la guerra. Recordemos al respecto que bajo la presión de Lloyd George, en marzo de 1919 el Consejo Supremo para el armisticio autorizó a los griegos a desembarcar en Esmirna, desembarco que se produjo en mayo de 1919, lo que dio lugar a una nueva guerra entre Grecia y Turquía, que habría de durar hasta septiembre de 1922 y que dejó desolada la Anatolia occidental en general y la ciudad de Esmirna en particular ${ }^{74}$. Tras el triunfo de Turquía, el acuerdo de paz con las potencias se logró definitivamente el 24 de julio de 1923 por el tratado de Lausana, que sustituyó al de Sèvres y del cual nació la Turquía moderna.

La guerra en cuestión afectó directamente a nuestro autor, Alexandre Ben-Guiat, quien, tras recuperar los turcos la ciudad de Esmirna en 1922, fue acusado de colaborar con los griegos y tuvo que abandonar la ciudad donde había nacido, muriendo también entonces su periódico El Meseret, así como los restantes periódicos judeoespañoles de Esmirna ${ }^{75}$.

\footnotetext{
${ }^{72}$ Ambos poemas se editan en Romero, Entre dos, cap. 12, núm. 120 y cap. 14, núm. 141.

${ }^{73}$ Editada en Romero, «Más poemas», págs. 131-200: núm. 10.

${ }^{74}$ Vid. al respecto Romero, Entre dos, cap. 13.

${ }^{75}$ Vid. al respecto BARQuín LóPEz, Edición, pág. 57.
} 


\section{GLOSARIO}

adeta (tc. âdeta) 'casi, de hecho; en realidad; simplemente, sencillamente'.-- afilú (hb. אפילו) 'incluso'.- aĵustado (cfr. fr. ajouter) 'completado, añadido'.- alḥad ('domingo'): noches de $\neg$ 'sábados por la noche' -- alḥajún: vid. nota 23.- altelic (tc. alttllk): cierta moneda turca, equivalente a seis piastras.amaría (argot) 'libra (turca) de oro'.- amocarse (cfr. DRAE s.v. mocar) 'sonarse'.- Antant (fr. Entente): (tb. Entente Cordiale, Triple Entente).- arovés 'al revés' .- atemado 'exterminado, aniquilado'.- Aydín: nombre de una ciudad de Anatolia.- bamiya (tc. bamya, bamye) 'quingombó'.- Beledié (tc. belediye) 'Ayuntamiento, Municipalidad'.- benivet: vid. yiné.- berequiet (tc. bereket) 'abundancia'.- bešlic (tc. beşlik) 'moneda turca de cinco piastras'.- bet haḥayim (hb. בית החיים) 'cementerio'.-- biero (cfr. fr. bière 'cerveza', it. birraio) 'cervecero'.- bira (tc. bira, it. birra) 'cerveza'.- biź biźé (tc. biz bize) 'en familia, en la intimidad'.- borecas (tc. sing. börek): pastelillos de hojaldre rellenos de carne, queso o verduras.- bulgurico (tc. bulgur 'trigo') 'triguito cocido y molido'.- buracos 'agujeros'.- cábot (cfr. tc. kaput bezi) 'tejido de algodón blanco, ligero y burdo'.- cabral: quizá 'cordero'.- caja: vid nota 55.calayileado: vid. nota 45.- campión (it. campione) 'modelo, muestra' .- carar (cfr. tc. kararinda) 'justo, oportuno'.- cart (tc. kart) 'reseco, duro'.- catifé (tc. kadife) 'terciopelo'.- chanaca (tc. çanak) 'escudilla, plato'.- Čheliḅón (cfr. tc. çelebi 'señor, don', título de distinción acordado a los notables de una ciudad o de una comunidad; también nombre propio): nombre propio.- chequear (alj. ג'יקיאר, cfr. tc. çek-) 'soportar, sobrellevar'.- chit (tc. çit) 'tela de algodón estampada'.- chorapes (tc. sing. çorap) 'calcetines'.- coltucchís (tc. sing. koltukçu) 'dueños de pequeños despachos de bebida'.- coro (cfr. fr. coeur, it. cuore) 'corazón'.- culaques (tc. sing. kulak) 'orejas, oídos'.- dertes (tc. sing. dert) 'pena(s), sufrimiento(s), preocupación(es), angustia(s)' .- dicat (tc. dikkat) 'atención, cuidado'.- duźico (cfr. tc. duz 'aguardiente de uvas'): vid. nota 29.embatacar 'cubrir de suciedad, de mierda'.- en'áyim: vid. nota 50.- enciscar

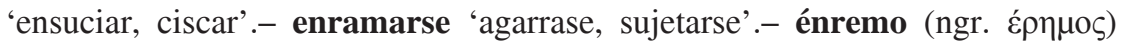
'nefasto, maldito'.- envedreado: vid. nota 46.- envereí: vid. nota 21.- ervía (alj. אירבייאה) 'arveja, guisante'.- escapar 'acabar, terminar'.- espirtos (ngr. sing. $\sigma \pi i \rho \tau 0)$ 'cerillas'; vid. nota 43.- estampado (cfr. it. stampare, fr. estamper, esp. estampar) 'publicado, impreso'.- fasulia (tc. fasulya, fasulye, ngr. фaбó $\lambda_{\mathrm{l}}$, $\phi a \sigma o u ́ \lambda$ ı) 'judía, alubia, habichuela'.- fernetico: vid. nota 30.- fidionda 'maloliente, hedionda'.- fiel 'hiel'.- fijón 'judía, alubia, habichuela'.- fitijos 'nie- 
tos'.- fraguar 'construir'.- fuíteš 'huyisteis'.- griña (ngr. $\gamma \rho$ '́vı $\alpha$ ) 'mal humor, rezongo'.-- grušes, dim. pl. grušicos (tc. sing. kurus, guruş 'piastra') 'monedas (-ditas), dinero (-rito)'.- haḥayim: vid. bet.- haločentos 'tropecientos, una fortuna'.- halvá (tc. helva, halva): dulce preparado con aceite de sésamo y azúcar y diferentes ingredientes, como almendras, nueces, miel, etc.- halvaĝ́í (tc. helvacl) 'vendedor de halvá' .- haminado (cfr. hb. חמין / hamín, tc. hamim 'agua caliente'): güevo $\neg$ 'huevo duro cocido con aceite y cáscaras de cebolla, que adquiere un color marrón'.- hasé (tc. hase, hasa) 'tela de algodón'; vid. nota 39.- Iźmir (tc. Izmir) 'Esmirna' - landrada, landre 'peste, landre' -- ma (it. ma, tc. ama) 'pero'.-- meĝit (tc. mecit, mecidiye): moneda turca de plata equivalente a 20 piastras.- megitim: vid. nota 35.- meldar 'leer' -- metalic, pl. metaliques (tc. sing. metalik, metelik): moneda turca de cobre de 10 piastras.- metes: vid. nota 31.- meźé (tc. meze) 'aperitivo'.- mirar de enfrente: vid. nota 54.- molde 'forma, manera'.- negro 'malo'.- nemsí (tc. Nemse, Nemçe) 'austriaco'.nobetchís (tc. sing. nöbetçi) 'el que está de guardia, vigilante' - - pachás (tc. sing. paça) 'patas'.- paltó (fr. paletot, it. palto, tc. palto) 'abrigo, sobretodo'.- parás (tc. sing. para) 'moneda(s), dinero'.- pasarse 'prescindir, abstenerse'.- patenta (al. patent, fr. patente) 'patente, derecho exclusivo'.- Pésaḥ (hb. פסח) 'Pascua', una de las tres festividades mayores, de peregrinación en tiempos bíblicos, en la que se conmemora el éxodo israelita de Egipto y la liberación del cautiverio; cae entre marzo y abril.- petaḥim (hb. פתחים) 'puertas'.-- petrollo (it. petrolio) 'petroleo'.- pišcul (tc. püskül) 'pompón del fez'.- Pitom (alj. פיתם, hb. פתם): vid. nota 17.- prasa (tc. prrasa) 'puerro'.- preto 'negro'.- pujar 'subir de precio'.- quiebarlic (tc. kibarlık) 'altanería, prepotencia'.- quief (tc. keyif) 'alegría, diversión, placer' -- quieftés (tc. sing. köfte) 'albóndigas'.- quiemur (tc. kömür) 'carbón vegetal'.- quiraguí (tc. kırağı) 'escarcha, helada'.- Ra'amsés (hb. רעמסס): vid. nota 17.- rahat (tc. rahat) 'tranquilo, reposado, calmado'.raquí (tc. rakl) 'aguardiente'.- rellevar 'sobrellevar, soportar'.- riźás (tc. sing. rida) 'pañuelos'; vid. nota 38.- sacaquié (ngr. бaxxáxı 'chaqueta') 'guerrera'; vid. nota 19.- salep (tc. salep, sa leb; cfr. DRAE, s.v. salep): bebida fermentada hecha a base de la fécula sacada de los tubérculos del satirión y de otras orquídeas, se toma caliente.- sardelas (it. sing. sardella, tc. sing. sardalya, sardalye, sardela) 'sardinas'.- שי šešit (alj. שישיט; cfr. tc. şuşe) 'lingote de oro o de plata'.-

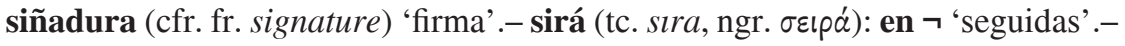
suḅia (tc. sübye): bebida dulce preparada a base de almendras molidas, pipas de melón, etc.- suvenir (fr. souvenir) 'recuerdo'.- tablas 'somier de madera; tb. (el) suelo'.- tacos 'talones del calzado'.- tašteado (cfr. tc. taş- 'desbordar, rebo- 
sar') 'rebosado'; vid. nota 32.- tierregośo 'terroso'.- top (tc. top) 'pieza completa de tejido'.- trabar 'soportar, sufrir' -- trato 'comercio'.- tufenc (tc. tüfek, tüfenk) 'fusil, escopeta'.- valiarse (esp. ant. avaliar, it. valersi) 'valerse, servirse de'.- vista: de $\neg$ 'inmediatamente, a toda prisa' .- y: tb. 'también' .- yatišear (tc. yetiş-) 'lograr, conseguir'.- yiné benivet: vid. nota 33 .

Recibido: 08/10/2013

Aceptado: 30/05/2015 